\title{
Zen and the Art of Higher Education Maintenance: Bridging Classic and Romantic Notions of Quality*
}

\author{
Patricia M. Shields \\ Texas State University
}

The justification for a university is that it preserves the connection between knowledge and the zest for life, by uniting the young and the old in the imaginative consideration of learning. The university imparts information but it imparts it imaginatively (Whitehead, 1929 p.139).

\section{Introduction}

In the fall of 1998, I chaired a university wide committee charged with assessing 120 strategic plans (academic and support) in light of the University's top goal of quality. The committee, which was composed of faculty and staff began discussing the meaning of quality in higher education. It was obvious from the discussion and emotion that quality and assessment had many meanings to faculty. Thus, I began a search for the meaning of quality in higher education. To my surprise, the source most often recommended by fellow faculty was Robert Pirsig's, Zen and the Art of Motorcycle Maintenance.

As I began exploring the issue, I found that the committee's problem- assessing our institution's strategic plans -confronts assessment issues broadly because assessment and strategic planning are complementary. In addition, university formal quality initiatives usually incorporate both planning and assessment.

\section{What is Quality?}

Quality is complicated and has many dimensions. The American Heritage Dictionary defines quality as "an inherent or distinguishing characteristic or property, a 
trait." It is also the "essential character or nature" and "superiority of kind, degree or grade of excellence." Quality is obviously a term that has many meanings. It is also associated with Deming's Total Quality Management movement.

\section{Two Views of Reality}

The problem with understanding quality often stems from two world views that give different meanings to the "essential character or nature" of a university or what defines university "excellence". In Zen and the Art of Motorcycle Maintenance, Robert Pirsig $(1974,49)$ seeks the meaning of quality (1). He begins by defining two seemingly conflicting "realities, one of immediate artistic appearance (romantic) and one of underlying scientific explanation (classic)".

One might observe these realities on a university campus in a debate over the value of assessment. One group supports the assessment process while the other group dismisses assessment maintaining that the really important aspects of the university can never be measured. Most university quality initiative rest upon the use of assessment. Hence, examining the conflict between these views has merit because the conflict influences the meaning of quality.

According to Pirsig, $(1974,61)$ romantic reality is primarily creative, imaginative, inspirational and intuitive. Feelings rather that fact predominate.

Whitehead's emphasis on imagination highlights the romantic nature of the university. "Imagination preserves the zest of life." (p. 139) Imagination

can only be communicated by faculty whose members themselves wear their learning with imagination. ...More than two thousand years ago the ancients symbolised learning by a torch passing from hand to hand down the generations. That lighted torch is the imagination of which I speak. The whole art in the organisation of a university is the provision of a faculty whose learning is lighted up with imagination. This is the problem of problems in university education (pp. 145-146). 
The classic view of reality relies on reason and evidence. Evidence is often collected as quantitative data. It is associated with using the scientific method to answer questions and address problems. Pirsig points out that behind the scientific explanations scientists often see an underlying form with aesthetic appeal that the romantic seldom sees.

When universities implement assessment strategies they most often rely on the classic mode of thought. There is an emphasis on measurement that those who adhere to the romantic vision find uncomfortable. Most Quality Initiatives, at first glance, are in the classic camp. After all, the Baldrige Award (2) definition of maximum quality is 1000 points. Ironically, this award transforms quality into quantity. How can imagination be captured in these criteria? The fear among those who identify with the romantic mode is that adoption of the classic view of Quality (3) will overwhelm the romantic vision and imagination and zest will be lost in the process.

\section{A Connection?}

The view of quality that is developed here seeks to overcome the problems with the seeming irreconcilable duality posed by the classic and the romantic visions. Pirsig $(1974,264)$ describes how the classic and romantic views can be united at a basic level. Quality wasn't classic Quality or romantic Quality. It was beyond both.

And by God, it wasn't subjective or objective either. It was beyond both those categories (pp. 212-213) ...Quality couldn't be independently related with either the subject or the object but could be found only in the relationship of the two with each other (p. 215).

In other words, Quality was not in the student or in the knowledge they acquired, rather it was in the relationship between the student and the knowledge. It was found in the processes that connect student and knowledge (processes that, hopefully, contain imagination). 
Romantic Quality correlated with instantaneous impressions. Classic Quality involved several considerations that extended over time. Romantic Quality contains the "present, and here and now of things." Classic Quality is "always concerned with more than just the present." From a romantic point of view, if a curriculum is working, why worry about it? However, if one considers the "present to be merely an instant between the past and the future, just a passing, moment, then to neglect the past and future for the present is bad Quality indeed." The curriculum may be working now, but do the students continue to be engaged in learning? Is the knowledge relevant in today's market? "Fussbudgetry from the romantic view, but good common sense from the classic." Pirsig finds " two different kinds of Quality but they no longer split Quality, itself. They were just two different time aspects of Quality, short and long" (Pirsig 1974, 223).

Pirsig (1974) points out the notion of Quality is deeply connected to caring because Quality and caring are internal and external aspects of the same thing. "A person who sees Quality and feels it as he works is a person who cares." A university that have faculty, staff and students that care about what they are doing are "bound to have some characteristics of Quality" (p.247). Unfortunately, it may be difficult to identify "caring" with certainty within university documents (plan, syllabus, Master's thesis). It is possible, however, to identify "not caring." For example, plans which are a thinly disguised call for more money or a dusted off version of last years plan demonstrate a lack of caring about the planning process and an unfortunate lack of Quality. A disorganized, minimal syllabus may preview a similar course. A department that ignores basic needs of its majors demonstrates a lack of caring (note: this is not a student as customer metaphor).

The role of caring is deeply embedded in Quality choices.

The difference between a good mechanic and a bad one, like the difference between a good mathematician and a bad one, is 
precisely this ability to select the good facts from the bad one on the basis of quality. He has to care! This is an ability about which formal traditional scientific method has nothing to say (p. 253).

The selection of what to include in a plan, syllabus or thesis reflects a level of caring or Quality. It also presents an opportunity for imagination.

Pirsig (1974) describes the university as a "Train of Knowledge" and uses this analogy to connect classic and romantic versions of quality in higher education.

Classic Knowledge, the knowledge taught by the Church of Reason, is the engine and all the boxcars. ...If you subdivide the train into parts you will find no Romantic knowledge anywhere. And, unless you're careful it's easy to make the presumption that's all the train there is. This isn't because Romantic Knowledge is nonexistent or even unimportant. It's just that so far the definition of the train is static and purposeless.

Romantic Quality, isn't any 'part' of the train. It's the leading edge of the engine a two-dimensional surface of no real significance unless you understand that the train isn't a static entity at all. A train really isn't a train if it can't go anywhere. In the process of examining the train and subdividing it into parts we've inadvertently stopped it, so that it really isn't a train we are examining.

The real train of knowledge isn't a static entity that can be stopped and subdivided. It's always going somewhere. On a track called Quality. And that engine and all those 120 boxcars are never going anywhere except where the track of Quality takes them; and romantic Quality, the leading edge of the engine, takes them along the track (p. 254).

The moving train analogy again reinforces that quality cannot be interpreted as static. It is associated with a continuous process. It is also infused with and directed by romantic notions; notions that might be found in vision or mission statements.

With Quality as a central undefined term, reality is, in its essential nature, not static but dynamic reality you never get stuck. It has forms but the forms are capable of change (p. 255).

The dynamic nature of quality implies a degree of flexibility. A University's vision is not a quest for certainty rather it is an articulation of an end-in-view which is capable of evolution. 
To put it more concrete terms: If you want to build a factory, or fix a motorcycle [build a university] ..then classical, structured dualistic subject-object knowledge, although necessary, isn't enough. You have to have some feeling for the quality of the work. You have to have a sense of what's good. That is what carries you forward. ... Its not just 'intuition,' not just unexplained 'skill' or 'talent.' It's the direct result of contact with basic reality, Quality which dualistic reason has in the past tended to conceal (p. 255).

A critical review of the formal Quality Initiative spelled out through the Malcom Baldrige Award reveal a surprising similarity to Pirsig's discussion of Quality. The next section develops these connections.

\section{The Quality Movement in Higher Education (4)}

Before proceeding to examine the formal quality initiative in light of Pirsig's insights about quality we will take a side trip to investigate some thoughts of John Dewey. John Dewey is a noted philosopher of education and also is known as a philosopher who battled dualism such as the romantic/classic split identified by Pirsig. In Democracy and Education he examines the properties of a good aim (goal) in education. The planning document is the formal document wherein the university specifies these aims as it tries to "create the future." Dewey (1916) argues that an aim in education must be an "outgrowth of existing conditions. It must be based upon a consideration of what is already going on; upon the resources and difficulties of the situation" (p.121). Like Pirsig, Dewey stresses process. In addition, in order to make sense of a goal/aim it is essential to examine "where we are."

One of the critical aspects of any plan is the "where we are" stage. It should be noted that the "where we are" phase should be infused with imagination and honesty. This is the phase where qualitative judgments guided by caring are so important. Using Pirsig's terms, the leading edge of the train is attended to. 
During the "where we are" phase university departments and divisions need to use processes which enhance and encourage creativity (i.e., retreats, meetings facilitated by outsiders). Concrete evidence about "where we are" is also essential if departments are to figure out how to improve (get better/enhance quality). The development of benchmarks is one way for a department to tell where it is.

Given the dynamic nature of Quality, the track is not fixed. Like sign posts, benchmarks mark and direct progress. Benchmarks that are developed with imagination and caring should contribute to Quality. They are also assessment tools that should be sensitive to both classic and romantic aspects of Quality. The image of the benchmarks that direct and mark progress is akin to the "value added" concept emphasized by the Baldrige Criterion(5).

Dewey (1916) stresses that the aim "as it first emerges is a mere tentative sketch. The act of striving to realize it tests its worth" (p. 122). Also, acting upon an aim usually brings to light "conditions which had been overlooked. This calls for revision of the original aim ... An aim must be flexible; it must be capable of alteration to meet circumstances." A good aim is also responsive, it can "affect desirable alterations." In short, a good aim "is experimental, and hence constantly growing as it is tested in action" (p. 123).

The flexible and experimental nature of the Quality concept makes it an ideal overriding goal. Quality as conceived by the Baldrige Award encourages departments to determine their own missions and goals. Ideally, departmental missions are developed taking into account changing circumstances. The missions and goals are concrete and at the same time flexible. It should be noted that the fast pace of technological change reinforces the need for flexibility.

Quality emerges from front end planning processes such as 1) asking tough questions (what is our vision of the ideal quality graduate -what do they know? What can they do?); and 2) establishing concrete strategies and concrete ways to collect 
evidence which mark progress. A quality plan is organized to make connections (connections between problems and goals; goals and objectives; objectives and strategies; problems and strategies; objectives and benchmarks; strategies and benchmarks/evidence; connections over time and connections with larger university purposes). A static view of Quality places connections in the background.

Departments can learn about changing circumstances through "stakeholder involvement." Stakeholders include people both internal and external to the department. Groups within the university community, particularly students, can help departments learn "where we are." External friends and associates of the university can provide useful information about changing circumstances. In the School of Business, for example, one would expect employers in the business community to be stakeholders with useful information about needed knowledge and skills.

Whitehead (1929) stresses that universities infuse knowledge with imagination.

For successful education there must always be a certain freshness in the knowledge dealt with. ...Knowledge does not keep any better than fish. ....Somehow [knowledge] must come to the students, as it were just out of the sea and with the freshness of its immediate importance (p.174). [italics added]

When stakeholder involvement helps to enhance the freshness of knowledge it contributes to the Quality of the university. The Baldrige (1995) award emphasizes the role of learning-centered education (6). The focus of higher education should be "on learning and the real needs of learners. Such needs derive from the requirements of the marketplace and the responsibilities of citizenship" (p. 3). Fresh ideas about marketplace needs and citizenship can emerge from discussions with interested stakeholders.

The Baldrige criterion also emphasizes the notion of continuous quality improvement. Quality is not static. It is ongoing. This obviously echoes the perspective 
of Pirsig and Dewey. The Quality initiative is also about delineating ends that grow up within an activity or process This is also known as-continuous process improvement.

Continuous improvement implies a commitment by everybody within the organization to an ongoing process of planning and testing improvements, evaluating outcomes, learning from failures, implementing and sustaining successes, planning and testing improvements. To be effective this commitment must be fully integrated into the philosophy of the institution, and the outlooks of its faculty, staff and students (Ruben 1995, 12).

This approach is consistent with Pirsig's (1974) key insight about quality: “Quality couldn't be independently related with either the subject or the object but could be found only in the relationship of the two with each other" (p. 215).

The Baldrige Award suggests that in order for continuous improvement and organizational learning to occur the university must "focus on key processes as the route to better results." (Baldrige 1995, 4) Obviously the relationship between student and knowledge/skills is through the process of teaching, the relationship between faculty and journal article is through the process of research/scholarship. Hence, the road to Quality must focus on core processes. The connection between core processes and value added (where we are/where we want to go) must be at the heart of the planning process. If these connections are weak, nonexistent or not concrete, it is difficult to mark our progress on the road to Quality. Also, attention should focus on the connection between core processes and imagination. Quality teaching lights the student's "torch" of imagination. Quality scholarship inspires others to join the inquiry. Quality service projects inspire dedication and caring about the job.

Part of the quality process necessarily involves identification of problems. An honest assessment of "where we are" should include a discussion of problems. In this case, "where we want to be" would include strategies (another kind of process) to address the problem and indicators that would provide evidence that there has been 
change ( things are getting "better"). Quality occurs when strategies connect to problems identified in the "where we are " stage.

Pirsig $(1974,255)$ referred to Harry Truman's common sense view as a concrete form of Quality. Truman focused on "what worked." How does one know whether a strategy "worked?" Specifying the necessary evidence ahead of time is one way. Plans enhance Quality when the connection between evidence and strategy are specified. In addition, strategies and their development should reflect/include imagination. Hence, any assessment of university plans should highlight "best practices" or innovative strategies that "work."

A common concern about assessment is that measurement itself could take so much time and effort that it stifles imagination and attention to core processes. Also, the desired outcome may be difficult to measure. In these cases, the concept of face validity might be helpful. There may be agreement within the system that a particular strategy, if implemented, will enhance a particular goal. For example, the university may believe that student safety is an important goal. A strategy to enhance safety is the installation of peepholes in dorm rooms. An indicator of success might simply be that the job is done. Connecting this strategy to crime rates or feelings of student safety might be pointless. Both crime rates and perceptions of safety are influenced by other circumstances. Perhaps frank discussion about strategies and face validity would be fruitful. It should be noted that evidence is used in both cases; however, the type of evidence is different.

Pirsig (1974) notes that the classic approach has always been the very best at 2020 hindsight. Providing evidence about "where you are." "It's good for testing the truth of what you think you know, but it can't tell you where you ought to go. Creativity, originality, inventiveness, intuition, imagination--'unstuckness,' in other words- are completely outside its domain" (p.251) [italics added]. 
The question of "where should we go" is central to the planning/assessment process. It is possible to choose from an array of possible futures and an array of ways to collect evidence about progress toward those futures. Quality comes to play in the choice. In other words, Quality/caring should guide the selection of priorities. To be effective and to contain this facet of Quality, planning documents must contain a sense of priorities.

\section{Conclusion}

The Baldrige Award links Quality and effective leadership. University leadership should treat strategic plans as useful tools as they fulfill their vital responsibility of providing a vision. A vision that is honest and that incorporates the role of caring, imagination and zest as part of the road to Quality. At the same time, university leadership must keep students, faculty and learning front and center in this vision.

\section{Acknowledgements}

*I would also like to thank members of the committee and SWT colleagues such as Gordon Thyberg, Suji Singh, Brian Montgomery, Sue Hall, Kathlyn Dailey, Kim Graves, Bruce Renfro, Sue McCullough, Vicki Meehan-Clark, Vince Luizzi, Nancy Warren, Jeff Kaufmann, George Weinberger, and Susan Griffith for their insight and encouragement. Special thanks to Kenneth Ashworth, former Texas Commissioner of Higher Education, for his suggestion about the title and Jerry Supple, President of Southwest Texas State University, for his concern about university quality.

Many insights for this article came through dialogue on the John Dewey ListServ (DEWEY-L@GANGES.CSD.SC.EDU). Special thanks go to Hugh Lawson, Bruce Kramer, Maynard Sanders, Warren Frisina, Teed Rockwell, Paul Zisman and Tom Burke.

\section{Endnotes}

(1) Pirsig (1974) defines quality. "Quality is characteristic of thought and statement that is recognized by a non thinking process. Because definitions are a product of rigid 
formal thinking, quality cannot be defined" (p. 184). It is, however, possible to speak of aspects or facets of quality.

(2) In 1987 the United States Congress established the Malcolm Baldrige Quality Award (Baldrige Award). The Award's purpose was to (a) promote quality throughout the United States; (b) recognize outstanding organisations and (c) foster sharing of best practice information throughout the U.S. Subsequently, a Baldrige Award has been established for higher education. The higher education Baldrige Award uses the following point system to assess quality. The categories considered and corresponding points are (1) Leadership 90, (2) Information and analysis 75, (3) Strategic and operational planning 75, (4) Human resource development and management 150, (5) Educational and business process management 150, (6) School performance results 230, (7) Student focus and student stakeholder satisfaction (230). Each category includes a set of items. For example, the educational and business category (5) includes the following items: (5.1) educational design, (5.2) education delivery, (5.3) education support services design and delivery, (5.4) research, scholarship, and service, (5.5) enrollment management, (5.6) business operations management. For more information on the Malcom Baldrige Award see Baldrige (1995).

(3) Quality is capitalized throughout because Pirsig capitalized the term "Quality."

(4) The language of the Quality movement usually reflects the classical perspective. The language is sometimes a barrier to communication. Do we really want to view a student as a consumer? Clearly, the student voice is important. The term "consumer," however, conjures up images of fast food. Hence, a second purpose of this section is to demonstrate that TQM ideas can be presented it terms that might be more palatable to academics.

(5) The value-added concept of excellence is selected because; (1) it places the major focus on teaching and learning strategies; (2) it poses similar types of challenges for all schools regardless of resources. When emphasizing the "concept of Excellence" institutions must build into the criterion demonstrated 'value-added' performance. Such performance has two manifestations: (1) "year-to-year improvement in key measures and/or indicators of overall performance; (2) demonstrated value-added leadership in overall performance relative to comparable school and/or to appropriate benchmarks"(Baldridge, 1995, 7).

(6) Key characteristics of learning centered education include "setting high developmental expectations and standards for all students. Learning centered education assumes "that students may learn in different ways and at different rates." (Baldridge 1995, 3) It also places major emphasis on active learning. It should be noted that this modern emphasis on active learning echoes the perspectives of both 
Dewey and Whitehead.

\title{
References
}

BALDRIGE, M. (1995). National Quality Award, (Education Pilot Criteria).

DEWEY, J. (1916). Democracy and Education, (New York: Macmillan).

PIRSIG, R. (1974). Zen and the Art of Motorcycle Maintenance, (New York: Bantam Books).

RUBEN, B. (1995). Tradition of Excellence: Higher Education Quality Self-Assessment Program, Assessment Criteria and Guide, (Dubuque, Iowa: Kendall/Hunt Publishing).

WHITEHEAD, A. N. (1929). The Aims of Education \& Other Essays, (New York: Macmillan).

\begin{abstract}
About the Author
Patricia M. Shields is a professor of Political Science and Director of the Master of Public Administration Program at Southwest Texas State University. She has diverse scholarly interests and has published over 35 articles in journals such as Armed Forces and Society, Public Administration Quarterly, Administration and Society, Journal of Police and Criminal Psychology, American Review of Public Administration, Transaction/Society and the Police Chief. She is currently investigating how to apply the pragmatism of John Dewey, Jane Addams, William James and Charles Sanders Peirce to the problems of public administration.
\end{abstract}

